\title{
Respon Peternak terhadap Pencegahan dan Pengobatan Penyakit Cacing Gastrointestinal pada Kambing di Desa Klopo Kecamatan Tegalrejo Kabupaten Magelang
}

\author{
Farmers Response on Prevention and Treatment Gastrointestine Worm Disease in Goat in Klopo \\ Village Tegalrejo District Magelang Sub-Province
}

\author{
Budi Purwo Widiarso*, Wida Wahidah Mubarokah \\ ${ }^{1}$ Politeknik Pembangunan Pertanian Yogyakarta Magelang, Jl. Mgelang-Kopeng Km 7 Purwosari \\ Tegalrejo Magelang
}

\section{Abstract}

Article history

Accepted: October 7, 2019;

Approved: August 13, 2019

* Corresponding author:

E-mail:

budipw2000@yahoo.com

\begin{abstract}
This study was conducted to determine the response of farmers to the prevention and treatment gastrointestine worm disease in goats and know factors that influencing farmer response Tools and materials used are stationery, questioner, folder, worm drug and vitamin of B complex. The respondents were 30 people. Data was taken from pre-test and post-test by conducting direct interview regarding prevention and treatment gastrointestine worm disease in goat by using questioner. Based on the regression analysis obtained by multiple linear equations as follows: $\mathrm{Y}=28.946+5.084 \mathrm{X} 1-0,215 \mathrm{X} 2+0,171 \mathrm{X} 3+0,548 \mathrm{X} 4+$ e. From model of regresion above, it can be intepreted that each increase in the vallue of $\mathrm{X} 1$ (education) equal to $1 \%$ will add respon equal to 5.084, each increase in the value of X2 (age) by $1 \%$ will reduce the respon by 0.215 , each increase of value of $\mathrm{X} 3$ (experience of farming) by $1 \%$ will add value of respon equal to 0.171 , and each increase of value of X4 (amount of the ownership of livestock) by $1 \%$ will add value of 0.548 . This study concluded that there was an increase in knowledge aspects of 14.87 with EP $82.6 \%$ and EPP $77.36 \%$, attitude aspects amounting to 10.47 with EP $90.88 \%$ and EPP $82.12 \%$ and skills aspects of 5.1 with EP $86.6 \%$ and EPP $79.19 \%$ and an increase in response value from aspects of knowledge, attitudes, and skills of 30.39\%, namely from a low response to a high response to the prevention and treatment of gastrointestinal worm disease in goats. Education is the most significant factor that has a very significant effect of $(\mathrm{P} 1 \leq 0.01)$ on the farmer response average
\end{abstract}

Keywords: prevention, treatment, gastrointestine worm, goat, response

\section{Pendahuluan}

Kambing adalah salah satu ternak popular yang banyak dipelihara di kalangan peternak di pedesaan. Ternak kambing pemeliharaannya mudah, cepat berkembangbiak, modal yang diperlukan relatif kecil dibanding dengan ternak sapi dan kerbau, bisa dipelihara di lahan sempit dan fesesnya bisa dimanfaatkan sebagai pupuk organik untuk tanaman. Dilihat dari potensinya maka ternak kambing dengan pemeliharaan dan perawatan yang baik akan diperoleh hasil yang baik pula (Widiarso, et al., 2017).

Usaha peternakan kambing di Indonesia masih menghadapi kendala yang mengakibatkan produktifitas masih rendah.
Hal ini pada umumnya disebabkan oleh berbagai jenis penyakit baik menular maupun tidak menular, penyakit sangat mempengaruhi pertumbuhan ternak kambing. Salah satu penyakit yang sering muncul adalah penyakit yang disebabkan oleh cacing gastrointestinal. Penyakit yang ini banyak terjangkit pada ternak ruminansia yang mengakibatkan pertumbuhan ternak lambat dan produktifitas menurun .

Pemeliharaan ternak kambing oleh peternak di desa Klopo Kecamatan Tegalrejo Kabupaten Magelang, masih kurang terutama dalam pencegahan dan pengobatan penyakit cacing gastrointestinal. Ternak-ternak yang mereka pelihara pada umumnya kurus dan 
bulunya kusam walaupun cukup pakan. Di Desa Klopo Kecamatan Tegalrejo terdapat 5 dusun yaitu Dusun Klopo, Dusun Busekan, Dusun Sangubanyu, Dusun Gendol dan Dusun Jaranan. Masing-masing dusun terdapat kelompok tani diantaranya adalah Kelompok Tani Budi Luhur, Kartika Tani, Tunas Mukti, Harapan, Cikalsari dan Sari Mulyo. Jumlah populasi ternak yang ada di Desa Klopo Kecamatan Tegalrejo, sapi potong sekitar 148 ekor, kambing 1312 ekor, dan domba 286 ekor.

Hasil identifikasi secara klinis dan laboratoris di Desa Klopo Kecamatan Tegalrejo terhadap ternak kambing menunjukan tanda-tanda terserang penyakit cacing gastrointestinal sehingga belum dapat memenuhi harapan peternak yaitu perkembangan tubuh yang maksimal dan memiliki nilai jual yang tinggi.

Penelitian ini bertujuan untuk mengetahui respon peternak terhadap pencegahan dan pengobatan penyakit cacing gastrointestinal tehadap ternak kambing dan mengetahui faktor-faktor yang mempengaruhi respon peternak terhadap pencegahan dan pengobatan penyakit cacing gastrointestinal pada ternak kambing.

\section{Materi dan Metode \\ Materi}

Bahan yang digunakan yaitu: obat cacing albendazole dan buah pinang. Alat yang digunakan adalah alat tulis, kuesioner, folder dan Elemen Keterampilan (EK)

\section{Metode}

Metode pengambilan sampel responden menggunakan metode purposive random sampling, dimana dari 5 kelompok tani yang ada di desa Klopo Kecamatan Teglarejo dipilih peternak yang mempunyai ternak kambing minimal 2 ekor, untuk setiap kelompok dipilih secara random 5 (lima) orang peternak sehingga di peroleh 30 responden. Jumlah ini dipilih agar dapat memenuhi syarat perhitungan statistik yang baik dengan penyebaran skor yang mendekati kurva normal (Rahmawati, 2008).

Metode pengambilan data dalam penelitian dilakukan dengan: observasi dan wawancara. Jenis data yang digunakan dalam penelitian adalah data primer dan data sekunder. Data primer diperoleh secara langsung dari peternak melalui hasil wawancara menggunakan kuesioner. Data sekunder diperoleh data keadaan penduduk Desa Klopo Kecamatan Tegalrejo Kabupaten Magelang.

Rancangan penelitian dilakukan dalam rangka pengukuran respon maupun faktorfaktor yang mempengaruhi terhadap pencegahan dan pengobatan penyakit cacing gilig pada ternak kambing di Desa Japan Kecamatan Tegalrejo Kabupaten Magelang. Responden berjumlah 30 orang diambil data awal (pra test) dan post test dengan cara melakukan wawancara langsung mengenai pencegahan dan pengobatan penyakit cacing gilig menggunakan alat bantu kuesioner yang mana tingkatan atau jenjang setiap gejala di ukur dengan menggunakan skala likert yaitu Respon Tinggi (5), Respon Sedang (3) Respon Rendah (1), dimana daftar pertanyaan merupakan alternatif pengungkapan permasalahan yang didasarkan pada variabel yang diamati, yaitu perubahan perilaku yang terdiri dari tiga aspek, yaitu aspek pengetahuan, sikap dan keterampilan. Faktorfaktor yang mempengaruhi respon dapat diuji menggunakan regresi linier berganda.

Variabel penelitian yang ingin diketahui adalah Pengetahuan, Sikap, Keterampilan (PSK) peternak terhadap pencegahan dan pengobatan penyakit cacing gastrointestinal pada ternak kambing.

\section{Analisis Data}

Analisis yang digunakan adalah analisis descriptive comperative yaitu membandingkan perubahan pengetahuan sebelum penyuluhan dan sesudah penyuluhan dengan rancangan pra eksperimental menggunakan Two Group Pra Test and Post Test Designs (Suryabrata, 2005).

\section{Hasil dan Pembahasan Respon Responden}

Hasil respon peternak terhadap pencegahan dan pengobatan penyakit cacing gastrointestinal pada ternak kambing adalah sebagai berikut :

Aspek Pengetahuan

Nilai aspek pengetahuan sebelum dan sesudah dilakukan penyuluhan dapat dilihat pada tabel 1. Berdasarkan tabel 1 di atas dapat diketahui pada aspek pengetahuan saat dilakukan pra test memiliki nilai sebesar 5,78 
(tidak tahu), setelah dilakukan treatment pada nilai post test menjadi 20,65 (tahu). Diperoleh peningkatan sebesar 14,87 atau dari tidak tahu menjadi tahu, Hal ini di sebabkan oleh tingkat pendidikan peternak dimana semua responden berpendidikan minmal SMP mampu menyerap ilmu pengetahuan dengan baik. Hal ini sesuai pendapat Mardikanto (2006) bahwa tingkat pendidikan yang dimiliki seseorang akan berpengaruh terhadap kapasitas/kemampuan belajar dan mamput memahami suatu teknologi/inovasi.

Tabel 1. Nilai aspek pengetahuan

\begin{tabular}{lccc}
\hline \multicolumn{1}{c}{ Pertanyaan } & Pra test & Post test & Peningkatan \\
\hline Pengertian penyakit cacing gastrointestinal & 1,46 & 4,93 & 3,47 \\
Tanda-tanda penyakit cacing gastrointestinal & 1,26 & 4,46 & 3,2 \\
Cara pencegahan penyakit cacing gastrointestinal & 1 & 4,06 & 3,06 \\
Cara memberikan obat cacing pada ternak kambing & 1 & 3,6 & 2,6 \\
$\begin{array}{l}\text { Cara mengobati penyakit cacing gilig dengan } \\
\text { menggunakan obat tradisional (serbuk buah pinang) }\end{array}$ & 1,06 & 3,6 & 2,54 \\
\hline$\quad$ Jumlah & $\mathbf{5 , 7 8}$ & $\mathbf{2 0 , 6 5}$ & $\mathbf{1 4 , 8 7}$ \\
\hline Rata - rata & $\mathbf{1 , 1 5 6}$ & $\mathbf{4 , 1 3}$ & $\mathbf{2 , 9 7 4}$ \\
\hline
\end{tabular}

Sumber: data primer

Peningkatan aspek pengetahuan peternak tersebut juga disebabkan oleh kesesuaian materi penyuluhan yang diberikan menggunakan metode ceramah, diskusi dan demontrasi cara dengan menggunakan alat bantu berupa folder, EK sehingga para petani lebih mudah memahami apa yang disampaikan. Sesuai dengan pendapat Mardikanto (2006) bahwa, dalam penyampaian penyuluhan tidak hanya dengan lisan, tetapi juga perlu alat bantu atau alat peraga agar materi lebih mudah diterima dan diserap serta lebih mengesankan.

Hasil analisis Pra test dan Post test pada aspek pengetahuan responden diketahui EP $82,6 \%$ dinyatakan efektif dan EPP 77,36 dinyatakan efektif. Efektifitas Penyuluhan untuk merubah perilaku aspek pengetahuan sebesar 82,6 \% di katakan efektif. Hal ini berarti kegiatan penyuluhan yang dilakukan dengan materi pencegahan dan pengobatan penyakit cacing gastrointestinal pada ternak kambing, dengan metode pendekatan individu dan kelompok dan dengan teknik ceramah, diskusi, serta demonstrasi cara dapat berkesan / berpengaruh terhadap perubahan aspek pengetahuan petani dari sebelum dilakukan penyuluhan dengan nilai 5,78 dan setelah diberi penyuluhan meningkat menjadi 20,65.

Efektifitas Perubahan Perilaku aspek pengetahuan sebesar 77,36\% dikatakan efektif dimana sasaran penyuluhan dapat menerima dengan baik materi yang diberikan dalam penyuluhan tersebut. Hal ini dapat dilihat dari perubahan pengetahuan dari sebelum dan sesudah dilakukan penyuluhan. Menurut Ginting (1993), pada dasarnya dalam setiap tahap dilakukan evaluasi ataupun pemantauan dengan tujuan untuk mengadakan perbaikan selama proses berlangsung.

Peningkatan aspek pengetahuan peternak tersebut juga disebabkan karena dalam kegiatan penyuluhan menggunakan teknik ceramah, diskusi dan demostrasi cara dengan menggunakan alat bantu berupa folder dan EK sehingga para peternak lebih mudah memahami apa yang disampaikan. Sesuai dengan pendapat Mardikanto (2006) bahwa dalam penyampaian penyuluhan tidak hanya dengan lisan, tetapi juga perlu alat bantu atau alat peraga agar materi lebih mudah diterima dan diserap serta lebih mengesankan.

Aspek Sikap

Berdasarkan Tabel 2 dapat dilihat nilai pra test pada aspek sikap menunjukkan nilai 12,25 dengan kategori respon setuju, sedangkan hasil post test menunjukkan nilai 22,72 dengan kategori respon setuju. Berdasarkan hasil analisis pra test dan post test terjadi peningkatan nilai sebesar 10,47. Hal ini disebabkan oleh adanya kegiatan penyuluhan yang tepat sasaran dalam arti baik materi maupun metode yang diberikan sesuai dengan kebutuhan peternak yaitu materi tentang 
pencegahan dan pengobatan penyakit cacing gilig pada ternak kambing dengan metode ceramah, diskusi dan demontrasi cara alat bantu yang digunakan berupa folder, EK (elemen ketrampilan) sehingga para petani lebih mudah memahami apa yang disampaikan, hal ini sesuai dengan pendapat Mardikanto dan Sutarni (2006), bahwa penyuluhan pertanian yang terutama ditujukan kepada petani dan keluarganya pada dasarnya dimaksudkan untuk mengubah dalam arti dapat meningkatkan perilakunya mengenai sikap yang lebih progresif dan motivasi yang lebih rasional.

Hasil analisis Pra test dan Post test pada aspek sikap responden dinyatakan efektif karena EP 90,88 \%, berarti bahwa program penyuluhan dengan materi pencegahan dan pengobatan penyakit cacing gastrointestinal pada ternak kambing dengan metode pendekatan individu dan kelompok serta dengan teknik ceramah, diskusi dan demonstrasi cara dapat berpengaruh dan berdampak bagi perubahan sikap petani terhadap teknologi pencegahan dan pengobatan penyakit cacing gastrointestinal pada ternak kambing dapat dilihat dari aspek sikap sebelum dan sesudah dilakukan penyuluhan dari ragu - ragu (nilai 12,25) menjadi setuju (nilai 22,72).

Tabel 2. Nilai aspek sikap

\begin{tabular}{|c|c|c|c|}
\hline Pertanyaan & Pra test & Post test & Peningkatan \\
\hline Membersihkan kandang secara periodik & 2,13 & 4,60 & 2,47 \\
\hline $\begin{array}{l}\text { Memberikan obat cacing untuk pencegahan penyakit } \\
\text { cacing gastrointestinal }\end{array}$ & 2,53 & 4,73 & 2,20 \\
\hline $\begin{array}{l}\text { Memanggil petugas keswan saat kambing sakit cacing } \\
\text { gastrointestinal }\end{array}$ & 2,26 & 4,00 & 1,74 \\
\hline Mencari rumput setelah pukul 09.00 WIB & 2,60 & 4,46 & 1,86 \\
\hline $\begin{array}{l}\text { Menggunakan obat cacing tradisional (serbuk buah } \\
\text { pinang) untuk mengobati penyakit cacing } \\
\text { gastrointestinal }\end{array}$ & 2,73 & 4,93 & 2,20 \\
\hline Jumlah & 12,25 & 22,72 & 10,47 \\
\hline Rata - rata & 2,45 & 4,54 & 2,09 \\
\hline
\end{tabular}

Sumber: data primer

Efektifitas Perubahan Perilaku sebesar 82,12 adalah efektif berarti penyuluhan yang dilaksanakan membawa perubahan bagi sikap peternak dari ragu - ragu dalam menerima teknologi pencegahan dan pengobatan penyakit cacing gastrointestinal pada ternak kambing (nilai 12,25) menjadi setuju (nilai 22,72) dan berarti respon petani tinggi. Menurut Ginting (1993), pada dasarnya dalam setiap tahap dilakukan evaluasi ataupun pemantauan dengan tujuan untuk mengadakan perbaikan selama proses berlangsung. Peternak diikutsertakan agar mereka mengetahui tingkat perubahan yang telah terjadi atau sejauh mana efektifitas penyuluhan dan efektifitas pengetahuan, sikap, dan keterampilan yang dapat dicapai.

\section{Aspek Keterampilan}

Berdasarkan Tabel 3 dapat dilihat nilai pra test pada aspek keterampilan menunjukkan nilai 3,56 dengan kategori respon kurang terampil, sedangkan hasil post test menunjukkan nilai 8,66 dengan kategori respon terampil. Berdasarkan hasil analisis pra test dan post test terjadi perubahan peningkatan nilai sebesar 5,1 atau dari kategori kurang trampil menjadi trampil. Hal ini disebabkan oleh adanya dampak dari kegiatan penyuluhan yang telah diberikan khususnya demonstrasi cara pemberian obat cacing sehingga peternak dapat melihat dan mempraktekan secara langsung pemberian obat cacing pada ternak kambing tersebut. Hal ini sesuai dengan pendapat Kartasapoetra (1988) mengatakan bahwa pengukuran aspek keterampilan dipengaruhi beberapa faktor berikut seperti. metode penyuluhan dengan pendekatan kelompok biasanya lebih efektif dan lebih bermanfaat apabila dilakukan terhadap kelompok tani. Dimana petani diajak 
dan dibimbing serta diarahkan untuk melakukan kegiatan yang lebih preduktif atas dasar kerjasama.. Teknik penyuluhan yang digunakan adalah ceramah dan diskusi dan demonstrasi cara dengan demikian petani ikut berpartisipasi petani akan lebih memahami materi yang disampaikan. Selanjutnya menurut
Mardikanto (2006), bahwa dengan petani melihat sendiri mereka akan lebih percaya dengan penyuluhan yang kita berikan dan dengan kepercayaan tersebut mereka akan terdorong untuk melakukan tindakan terhadap inovasi baru yang diterima

Tabel 3. Nilai aspek keterampilan

\begin{tabular}{cccc}
\hline \multicolumn{1}{c}{ Pertanyaan } & Pra test & Post test & Peningkatan \\
\hline $\begin{array}{l}\text { Pemberian obat cacing pada ternak dengan } \\
\text { menggunakan obat cacing kimia }\end{array}$ & 1,30 & 4,13 & 2,83 \\
Cara apabila obat cacing susah diaplikasikan & 2,26 & 4,53 & 2,27 \\
\hline Jumlah & $\mathbf{3 , 5 6}$ & $\mathbf{8 , 6 6}$ & $\mathbf{5 , 1 0}$ \\
\hline Rata -rata & $\mathbf{1 , 7 8}$ & $\mathbf{4 , 3 3}$ & $\mathbf{2 , 5 5}$ \\
\hline
\end{tabular}

Sumber: data primer

Hasil analisis Pra test dan Post test pada aspek keterampilan responden dinyatakan efektif karena EP 86,6 \%. Hal ini berarti program penyuluhan yang telah dilakukan dapat berdaya guna karena dapat merubah keterampilan dari tidak terampil menjadi trampil. EPP 79,19 dinyatakan efektif dapat dilihat dari peningkatan perubahan aspek keterampilan peternak dari tidak trampil memberikan obat cacing pada ternak kambing menjadi trampil.

\section{Peningkatan Nilai Respon}

Berdasarkan Tabel 4, nilai respon pra test memiliki nilai sebesar 21,66 atau (nilai rendah), setelah dilakukan treatmen pada nilai post test menjadi 52,05 atau (nilai tinggi). Dengan demikian terjadi peningkatan sebesar 30,39 atau dari respon rendah menjadi respon tinggi, Hal ini di sebabkan oleh: tingkat pendidikan peternak dimana semua responden rata-rata sudah berpendidikan minimal SMP.
Hal ini sesuai pendapat Mardikanto (2006) bahwa tingkat pendidikan yang dimiliki seseorang akan berpengaruh terhadap kapasitas/kemampuan. Padmowiharjo (2002), menyatakan bahwa, semakin tinggi tingkat pendidikan petani maka pola pikir dan kemampuan merespon teknologi baru

Umur responden terbanyak adalah 36-49 tahun dengan persentase $43,33 \%$ yang merupakan umur produktif, Junaidi (2007) mengatakan semakin tinggi umur semakin sulit baginya untuk menyerap dan menerima suatu inovasi yang diberikan.

Pengalaman beternak responden rata-rata 4 - 12 tahun, sehingga diharapkan dengan pengalaman yang cukup tinggi maka tingkat respon terhadap pencegahan dan pengobatan penyakit cacing gilig juga semakin tinggi. Junaidi (2007) menyatakan bahwa, pengalaman merupakan faktor personal yang berpengaruh terhadap perilaku seseorang.

Tabel 4. Nilai respon

\begin{tabular}{lccc}
\hline \multicolumn{1}{c}{ Nilai } & Jumlah (orang) & Post test & Persentase (\%) \\
\hline Pengetahuan & 5,80 & 20,66 & 12,54 \\
Sikap & 12,26 & 22,73 & 4,40 \\
Keterampilan & 3,60 & 8,66 & 3,66 \\
\hline \multicolumn{1}{c}{ Jumlah } & $\mathbf{2 1 , 6 6}$ & $\mathbf{5 2 , 0 5}$ & $\mathbf{3 0 , 3 9}$ \\
\hline
\end{tabular}

Sumber: data primer

$$
\mathrm{O} 1(21,66) \quad \mathrm{O} 2(52,05)
$$

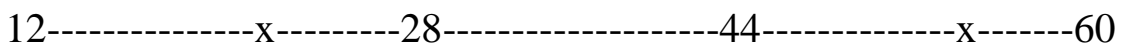

Rendah

Sedang

Tinggi 
Kepemilikan ternak rata - rata peternak mempunyai ternak lebih dari satu ekor ini terlihat dari jumlah kepemilikan ternak responden yaitu 2-4 ekor sebanyak 14 orang atau $(46,66 \%)$. Hal ini sesuai dengan pendapat Iswandari (2006) menyatakan bahwa, peternak yang memiliki ternak dengan jumlah banyak dan dikelola sendiri akan mempunyai kemauan yang tinggi dalam merespon, memperbaiki usaha tani ternaknya.

Peningkatan respon peternak tersebut mungkin karena kesesuaian materi penyuluhan yang diberikan menggunakan metode ceramah, diskusi dan demontrasi cara dengan menggunakan alat bantu berupa folder, EK sehingga para peternak lebih mudah memahami apa yang disampaikan. Sesuai dengan pendapat Mardikanto (2006) bahwa, dalam penyampaian penyuluhan tidak hanya dengan lisan, tetapi juga perlu alat bantu atau alat peraga agar materi lebih mudah diterima dan diserap serta lebih mengesankan.

Berdasarkan analisis regresi didapatkan persamaan linear berganda sebagai berikut: $\mathrm{Y}=28.946+5.084 \mathrm{X} 1-0,215 \mathrm{X} 2+0,171 \mathrm{X} 3+$ $0,548 \mathrm{X} 4+\mathrm{e}$

Dari model regresi diatas dapat di artikan bahwa setiap peningkatan nilai X1 (pendidikan) sebesar $1 \%$ akan menambah nilai respon sebesar 5.084, setiap peningkatan nilai X2 (umur) sebesar $1 \%$ akan mengurangi nilai respon sebesar 0,215 , setiap peningkatan nilai X3 (pengalaman beternak) sebesar $1 \%$ akan menambah nilai respon sebesar 0,171 dan setiap peningkatan nilai X4 (jumlah kepemilikan ternak) sebesar $1 \%$ akan menambah nilai respon sebesar 0,548.

Berdasarkan Uji Determinasi (Adjusted R Square), pendidikan, umur, pengalaman dan jumlah kepemilikan ternak secara bersama sama mempengaruhi respon peternak terhadap inovasi teknologi pencegahan dan pengobatan penyakit cacing gilig pada ternak kambing sebesar 47,4 \% (Adjusted $\mathrm{R}^{2}=0,474$ ) sedangkan 52,6\% dipengaruhi oleh faktorfaktor lain diluar persamaan. Semakin besar $\mathrm{R}^{2}$ (mendekati 1) semakin baik hasil regresi tersebut (semakin besar variabel independen dapat menjelaskan variabel dependen dan semakin mendekati 0 maka variabel independen secara keseluruhan semakin kurang bisa menjelaskan variabel dependen (Mubyarto, 1999).

\section{Kesimpulan}

Hasil kajian dapat disimpulkan bahwa tingkat respon peternak terhadap pencegahan dan pengobatan penyakit cacing gastrointestinal pada ternak kambing meningkat dari respon rendah $(21,66)$ menjadi respon tinggi $(52,05)$. Faktor pendidikan dan umur berpengaruh sangat signifikan terhadap respon peternak ( $\mathrm{P} \leq 0,01)$, sedangkan secara bersama-sama faktor pendidikan, umur, pengalaman beternak, jumlah ternak, berpengaruh sangat signifikan terhadap peningkatan respon peternak $(\mathrm{P} \leq 0,01)$.

\section{Daftar Pustaka}

Beriajaya dan A. Husein. 2003 Efikasi pemberian antelmintik golongan levamisole dan ivermectin pada peternakan domba yang terinfeksi cacing yang resisten terhadap antelmintik golongan benzimidazole. Prosiding Seminar Nasional Peternakan dan Veteriner, Puslitbang Peternakan. Bogor.

Beriajaya. 1986. Pengaruh albendazole terhadap infeksi cacing nematoda saluran pencernaan pada domba lokal di Daerah Cirebon. Jurnal Penyakit Hewan. 18 (31) : $54-57$.

Brotowidoyo, M, D. 1987. Parasit dan parasitisme. PT. Melton. Jakarta.

Ginting, E. 1994. Pokok pikiran penerapan metode penelitian sosial dalam program kuliah kerja lapang. Universitas Brawijaya, Malang.

Haryuningtyas, D., Beriajaya dan G.D. Gray. 2001. Resistensi antelmintik golongan benzimidazole pada domba dan kambing di Indonesia. Prosiding Seminar Nasional Teknologi Peternakan dan Veteriner, Puslitbang Peternakan, Bogor.

Iswandari. 2006. Respon petani terhadap pasca panen ubi kayu di Kecamatan Playen Kabupaten Gunung Kidul. Skripsi Fakultas Pertanian UGM Yogyakarta.

Junaidi. 2007. Pemahaman tentang adopsi, difusi dan inovasi (teknologi) dalam penyuluhan pertanian. http://database.deptan.go.id:8081/portalpen yuluhan 
Kantor Informasi dan Komunikasi Pemerintah Propinsi Jawa Tengah Tahun 2004. http://www.google.com/search?q=kependu dukan+kantor+informasi+dan+komunikasi + pemerintah+provinsi+jawa+tengah $\& \mathrm{hl}=\mathrm{e}$ n\&prmd=ivns\&ei=RO.

Kartasapoetra. 1988. Metodologi Penelitian Sosial dan Pendidikan Teori-Aplikasi. Bumi Aksara. Jakarta.

Mardikanto, T dan Sutarni. 1982. Petunjuk Penyuluhan Pertanian. Usaha Nasional Surabaya.

Mardikanto,T. 2006. Prosedur Penelitian untuk Penyuluhan Pembangunan dan Pemberdayaan Masyarakat. Prima Theresia Pressindo. Surakarta.

Mardikanto,T.2009. Sistem Penyuluhan Pertanian. Lembaga pengembangan pendidikan (LPP) UNS dan Pencetakan (UNS Press). Surakarta.
Mubyarto, 1999. Reformasi Sistem Ekonomi dari Kapitalisme Menuju Ekonomi Kerakyatan. Aditia Media Yogyakarta.

Padmowihardjo, S. 2002. Metode Penyuluhan Pertanian. Universitas Terbuka. Jakarta.

Peraturan Menteri Pertanian Nomor 27 Tahun 2007 tentang "Pedoman Pembinaan Kelembagaan Petani”.2007.

Subekti, S, S. Mumpuni, S. Koesdarto dan H. Puspitawati. 1996. Ilmu Penyakit Nematoda. Fakultas Kedokteran Hewan. Universitas Airlangga. Surabaya.

Suryabrata. 2005. Psikologi Pendidikan. Raja Grafindo persada. Jakarta.

Widiarso, B.P., Wisnu, N., Kurniasih, Joko, P. 2017. Potensi daun bambu sebagai agen anthelmetika pada ternak kambing. Jurnal Pengembangan Penyuluhan Pertanian. 13 (25). 